\title{
SIMULAÇÃO DE ANÁLISE DE INVESTIMENTO PARA INSTALAÇÃO DE UMA PEDREIRA NO MUNICÍPIO DE CATALÃO/GO
}

\author{
Marcos Vinicius Agapito Mendes 1,2 \\ Andressa Cristina Costa Reis \\ Bruna de Oliveira Teodoro' \\ Eskarlet Amorim Rizzo ' \\ Flávio Augusto Santos e Sousa '
}

\section{Resumo}

Após períodos turbulentos nos últimos anos, os setores de mineração e construção civil apresentaram considerável recuperação em 2017. Consequentemente, a comercialização de agregados para construção reaquece, principalmente em cidades com alta taxa de crescimento, destacando-se a cidade de Catalão no interior do estado de Goiás. O município apresenta-se entre os maiores PIBs do estado. Diante desta situação, este estudo tem como objetivo realizar a simulação de uma análise de investimento para instalação de uma pedreira na região de Catalão/GO. O primeiro passo consistiu na determinação da produção necessária, obtida em função do consumo de agregado (brita) na região. Na sequência, foi definido e dimensionado os equipamentos necessários a lavra do material, elaborado o fluxograma do beneficiamento do material e estabelecido do balanço de massas em função da produção horária necessária, permitindo a seleção e dimensionamento dos equipamentos de usina. Uma cotação dos custos para aquisição dos equipamentos foi realizada junto aos fabricantes. O passo seguinte consistiu em definir custos com insumos, mão de obra, obras de alvenaria e infraestrutura necessárias. Os dados permitiram a elaboração de gráficos com cenários diferentes de retorno do investimento inicial. Os resultados apresentados pelos cenários 2 e 6 foram melhores que os demais. Entretanto, cada um possui características particulares que devem ser levadas em consideração, as quais dependem do perfil de investimento almejado.

Palavras-chave: Simulação; Avaliação econômica; Pedreira.

\section{INVESTMENT ANALYSIS SIMULATION FOR INSTALLATION OF A QUARRY IN THE MUNICIPALITY OF CATALÃO/GO}

\begin{abstract}
After turbulent periods in recent years, the mining and construction sectors showed a considerable recovery in 2017. As a result, the commercialization of construction aggregates reheats, especially in cities with high growth rates, especially in the city of Catalão in the interior of the state of Goiás. The municipality is among the largest PIBs in the state. Given this situation, this study aims to simulate an investment analysis for the installation of a quarry in the region of Catalão/GO. The first step was to determine the production required, as a function of aggregate consumption (gravel) in the region. After that, the equipment needed to surface mining was defined and dimensioned, the flow chart for the material processing was established and the mass balance was established as a function of the hourly production required, allowing the selection and sizing of the plant equipment. A quotation of the costs for equipment acquisition was made with the manufacturers. The next step was to define costs with inputs, labor, masonry and infrastructure needed. The data allowed the elaboration of graphs with different scenarios of return of the initial investment. The results presented by scenarios 2 and 6 were better than the others. However, each one has particular characteristics that must be taken into account, which depend on the desired investment profile.
\end{abstract}

Keywords: Simulation; Economic evaluation; Quarry.

'Departamento de Engenharia de Minas, Universidade Federal de Goiás - UFG, Catalão, GO, Brasil.

${ }^{2}$ Departamento de Mineração, Serviço Nacional de Aprendizagem Industrial - SENAl, Catalão, GO, Brasil. E-mail: marcos.vinicius.agapito@gmail.com

2176-1523 (C) 2019 Associação Brasileira de Metalurgia, Materiais e Mineração. Published by ABM. This is an open access paper, published under the Creative Commons CC BY-NC-ND license (Attribution-NonCommercial-NoDerivs) - https://creativecommons.org/licenses/ by-nc-nd/4.0\%. 


\section{INTRODUÇÃO}

No estudo de viabilidade econômico-financeira, há variadas técnicas para avaliação de investimentos, cada método apresentando sua vantagem e desvantagem, de acordo com a análise feita. Porém, todos fornecem conhecimento da situação econômico-financeira do investimento, permitindo a organização analisar se o projeto é economicamente viável ou não, auxiliando nas decisões futuras.

O fluxo de caixa é um instrumento de gestão financeira que projeta para períodos futuros todas as entradas e as saídas de recursos financeiros do caixa do empreendimento [I-5]. De fácil elaboração para as empresas que possuem seus fluxos financeiros bem organizados, ele deve ser utilizado para controle e, principalmente, como instrumento na tomada de decisões $[3,4]$.

É uma estrutura flexível, no qual o empresário deve inserir informações de entradas e saídas conforme as necessidades da empresa. Deste modo, é possível elaborar a estrutura gerencial de resultados, a análise de sensibilidade, calcular a rentabilidade, lucratividade, ponto de equilíbrio e o prazo de retorno do investimento. Assim, é possível verificar a saúde financeira do negócio, obtendo uma resposta clara sobre as possibilidades de sucesso do investimento e do estágio atual da empresa [1-5].

A mineração é um setor da economia que envolve altos investimentos para instalaçãode um empreendimento. Uma análise de viabilidade econômica garante o sucesso do negócio, devendo ser realizada por profissionais experientes e qualificados.

A pedreira caracteriza-se, normalmente, como um empreendimento mineiro de pequeno ou médio porte. Fornece agregados para construção civil em todas as regiões do Brasil, sendo a descoberta e instalação de novas minas condicionada pela demanda de consumo no local em questão. Em 2017, a produção nacional de agregados, de acordo com dados do IBRAM [6], chegou ao patamar de 420 milhões de toneladas, tornando este um dos principais produtos da indústria de mineração.

A viabilidade econômica de instalação de uma pedreira deve ser analisada com cautela, principalmente em função do baixo preço de venda por tonelada do material e o alto custo do frete para distribuição do produto. Portanto, a localização do empreendimento está intimamente ligada a viabilidade econômica de instalação.

Os agregados são classificados em areia (agregado miúdo) e brita (agregado graúdo). Este último é proveniente do processo de cominuição e classificação de vários tipos de rochas. Estes fragmentos de rocha são comercialmente classificados como rachão, gabião, brita graduada, brita corrida, brita I, brita 2, brita 3, brita 4, brita 5, pedrisco ou brita 0 , pó de pedra e areia de brita, cada um com granulometrias específicas bem definidas [7].

Considerando a cidade de Catalão/GO, sua população apresentou um crescimento de aproximadamente $16,1 \%$ entre 2010 e 20I7, saltando de 86.647 [8] para I00.590 [9] habitantes. De 2010 a 2015 Catalão esteve entre os cinco municípios do estado com maior PIB [I0]. Nos últimos anos, diversos bairros novos foram inaugurados no município. A população que migra para a cidade aumenta a cada ano, principalmente em função das universidades e empresas instaladas no local. Isto viabiliza o crescimento do setor de construção civil, com consequente aumento na demanda agregados para construção.

Diante da importância dos agregados para a construção civil e sua grande representatividade na produção mineral brasileira, o correto dimensionamento de pedreiras torna-se essencial para garantia de qualidade dos produtos comercializados e sustentação financeira do negócio perante o mercado competitivo. Neste contexto, insere-se o objetivo deste estudo, que busca realizar a simulação de uma análise de investimento para instalação de uma pedreira na região de Catalão/GO.

\section{MATERIAIS E MÉTODOS}

Visando a simulação de uma análise de investimento para implantação de uma pedreira na região de Catalão/GO, o primeiro passo consistiu em fixar a produção mensal do empreendimento em 56 mil toneladas de agregado graúdo (brita), dado estipulado após pesquisas da demanda pelo produto em lojas de comercialização de materiais para construção no município em questão.

Considerações como operação em turno único de 8 horas diárias, de segunda a sexta-feira, uma hora para refeição, realizada na empresa e terceirização das operações de desmonte de rochas foram realizadas de acordo com conhecimento prático vivenciado em empreendimentos semelhantes.

O basalto, rocha com densidade de $2,8 \mathrm{~g} / \mathrm{cm}^{3} \mathrm{e}$ empolamento de $33 \%$ [I I], muito comum na região, foi considerado como matéria prima para produção do agregado. Também ficou estabelecida como responsabilidade do cliente a retirada do produto na empresa.

Com a definição do layout do empreendimento, foi possível definir a distância média de transporte entre a mina e o britador (DMT) como 700 metros. O dimensionamento dos equipamentos de carregamento e transporte, juntamente com a consulta a catálogos de fabricantes, possibilitou 0 estabelecimento do tempo de ciclo em 4,9 para os caminhões e 3 minutos para a carregadeira.

Os custos de aquisição (CAPEX) e operação (OPEX) dos equipamentos foram obtidos através de entrevista com um representante da empresa BRASIF Máquinas [12] e catálogos de fabricantes, e os de infraestrutura através de planilhas disponibilizadas pelo Sindicado da Indústria da Construção Civil no Estado de Goiás (SINDUSCON-GO) [13]. Custos com mão-de-obra foram baseados nos pisos salariais.

Os custos com desmonte de rochas utilizando explosivos foram obtidos com a empresa Britago [14], e os custos energéticos segundo a empresa Pedreira Goiás [15]. 
Os custos com alimentação foram baseados no preço de refeições na região de instalação do empreendimento. Estimou-se os gastos com combustível de acordo com a potência dos equipamentos e cotação do diesel à época.

O preço de venda adotado no estudo é o mesmo praticado pela Pedreira Goiás [15], sendo a demanda pelos produtos estimada através da média de venda de 14 empresas fornecedoras de materiais para construção em Catalão/GO.

Buscando analisar a viabilidade do investimento, considerou-se que o empreendimento inicia com $30 \%$ da capacidade total, aumentando gradativamente a produção em $10 \%$ a cada mês, até atingir o teto máximo de $56 \mathrm{mil}$ toneladas/mês. Os meses com saldo negativo no fluxo de caixa foram zerados através de empréstimos, pagos em parcelas iguais, minimizando o impacto ao lucro final. Os juros aplicados ao pagamento do CAPEX (investimento inicial) foram tomados como a média das últimas taxas SELICs emitidas pelo Banco Central do Brasil em 2017 [16], o que corresponde a $0,725 \%$ ao mês. Por fim, foi considerado um valor de CFEM igual a I,5\% da produção.

\section{RESULTADOS E DISCUSSÃO}

Para análise da viabilidade de instalação do empreendimento foi necessário o planejamento do fluxograma de processos a ser adotado, o qual é representado esquematicamente pela Figura I.

De acordo com o dimensionamento das operações de lavra e beneficiamento, ficou estabelecida a necessidade de duas carregadeiras, dois caminhões, três peneiras vibratórias, 125 metros de transportador de correia, um britador de mandíbulas e um britador cônico, totalizando um custo final de $R \$ 3.555 .000,00$ para aquisição (Tabela I). Para construção das obras de infraestrutura correspondente a dois banheiros de $6 \mathrm{~m}^{2}$, um refeitório de $18 \mathrm{~m}^{2}$, um escritório com banheiro com $30 \mathrm{~m}^{2}$, oficina de manutenção com $60 \mathrm{~m}^{2}$ e um galpão para maquinário com $240 \mathrm{~m}^{2}$, ambos definidos com base no layout do empreendimento, estima-se um custo de $R \$ 25 \mathrm{I} .586,00$ (Tabela 2). Sendo assim, os custos com investimento (CAPEX) totalizaram $R \$ 3.806 .586,00$.

Os custos operacionais (OPEX) com salários, combustível, desmonte de rochas com explosivos, alimentação, energia, manutenção, impostos, dentre outros, totalizaram $\mathrm{R} \$ 559.566,36$ mensais, os quais são detalhados na Tabela 3 .

O lucro bruto mensal do empreendimento depende do preço de venda do produto. De acordo com dados da Pedreira Goiás [15], todos os produtos serão comercializados à preço padrão de $\mathrm{R} \$ 32,00$ por tonelada. Logo, uma produção mensal de 56 mil toneladas gerará lucro bruto de $R \$ 1.792 .000,00$ mensal.

Os dados apresentados permitiram a simulação de seis situações para o pagamento do investimento (CAPEX) em equipamentos e infraestrutura. As três primeiras situações consistem no pagamento logo no primeiro mês, alterando somente o número de parcelas em 24 (Figura 2), 12 (Figura 3) e 6 (Figura 4) meses. As últimas três situações (Figuras 5, 6 e 7) são semelhantes as anteriores, entretanto, com o pagamento da primeira parcela somente após seis meses do startup do empreendimento mineiro.

A Figura 8 permite uma comparação entre os lucros obtidos em cada proposta ao longo de 12 meses e a Figura 9 mostra os juros pagos em cada situação.
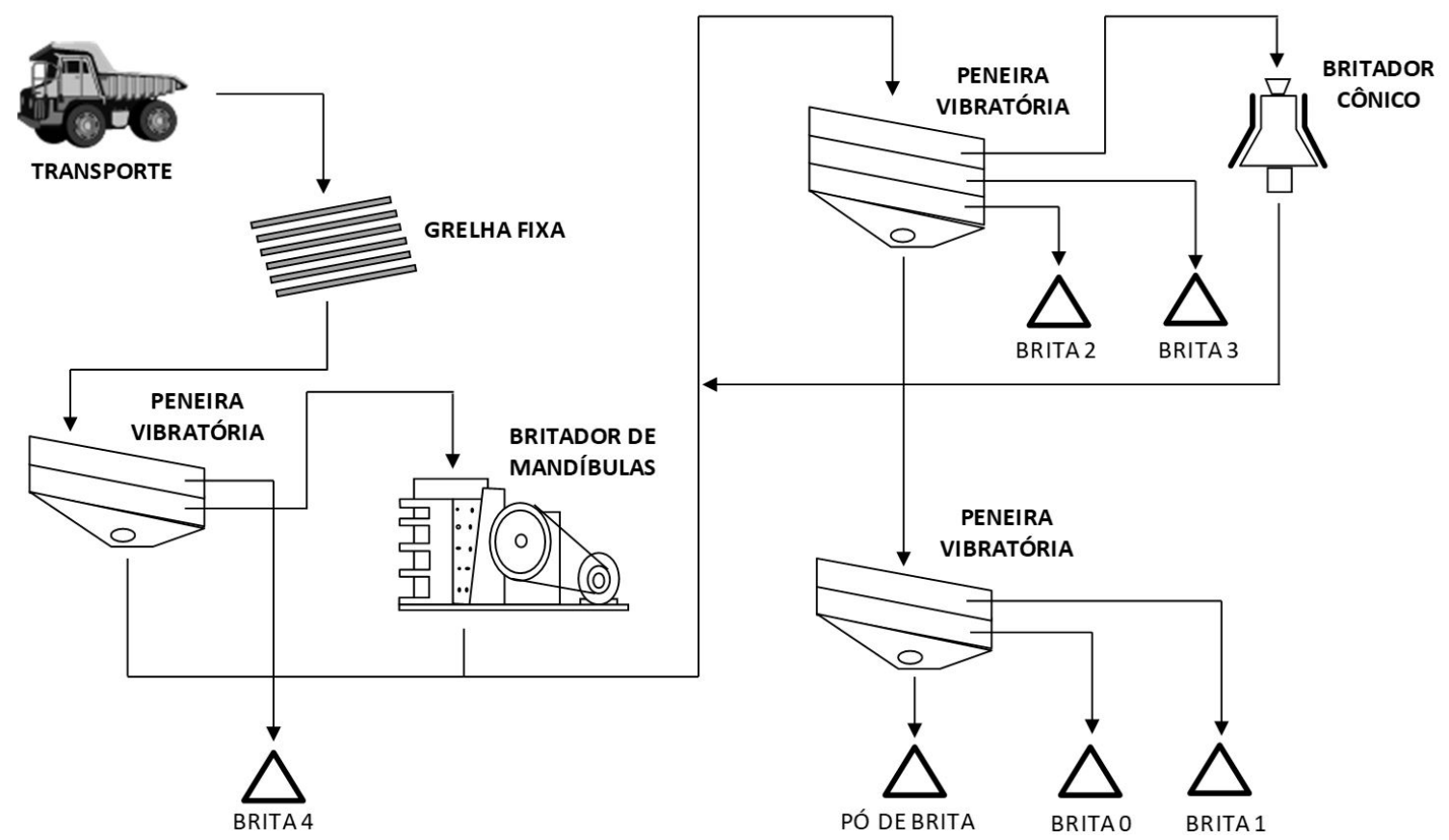

Figura I. Fluxograma esquemático para obtenção de agregados para construção civil a partir de rocha basáltica. 
Tabela I. Custos de aquisição de equipamentos (CAPEX) do empreendimento

\begin{tabular}{lcrr}
\hline \multicolumn{1}{c}{ DESCRIÇÃOO } & CUSTO UNITÁRIO (R\$/und) & QUANTIDADE & CUSTO TOTAL (R\$) \\
\hline Carregadeira & $250.000,00$ & 2 & $500.000,00$ \\
Caminhão & $350.000,00$ & 2 & $700.000,00$ \\
Grelha Fixa & $5.000,00$ & $\mathrm{I}$ & $5.000,00$ \\
Grelha Vibratória & $50.000,00$ & $\mathrm{I}$ & $50.000,00$ \\
Peneira Vibratória & $50.000,00$ & 3 & $150.000,00$ \\
Correia Transportadora & $2.000,00^{\prime}$ & $125^{2}$ & $250.000,00$ \\
Britador de Mandíbula & $1.000 .000,00$ & $\mathrm{I}$ & $1.000 .000,00$ \\
Britador Cônico & $950.000,00$ & I & $950.000,00$ \\
& & TOTAL & $3.555 .000,00$ \\
\hline
\end{tabular}

Obs.: 'Custo por metro (R\$/m); ${ }^{2}$ Quantidade em metros $(\mathrm{m})$.

Tabela 2. Custo com obras de infraestrutura (CAPEX) do empreendimento

\begin{tabular}{lccc}
\hline \multicolumn{1}{c}{ DESCRIÇÃO } & CUSTO $\left(\mathbf{R} \$ \mathbf{m}^{2}\right)$ & ÁREA $\left(\mathbf{m}^{2}\right)$ & CUSTO TOTAL $(\mathbf{R} \$)$ \\
\hline Banheiros & 816,15 & 12 & $9.793,80$ \\
Refeitório & 816,15 & 18 & $14.690,70$ \\
Escritório (C/ banheiro) & 816,15 & 30 & $24.484,50$ \\
Oficina de manutenção & 675,39 & 60 & $40.523,40$ \\
Galpão para maquinário & 675,39 & 240 & $162.093,60$ \\
& & TOTAL & $251.586,00$ \\
\hline
\end{tabular}

Tabela 3. Custos operacionais (OPEX) do empreendimento

\begin{tabular}{|c|c|c|c|}
\hline DESCRIÇÃO & CUSTO UNITÁRIO (R\$/mês) & QUANTIDADE & TOTAL (R\$/mês) \\
\hline Administração & $1.613,19$ & 2 & $3.226,38$ \\
\hline Engenheiro de Minas & $9.679,14$ & I & $9.679,14$ \\
\hline Faxineiro & $1.613,19$ & 2 & $3.226,38$ \\
\hline Mecânico & $2.807,55$ & I & $2.807,55$ \\
\hline Operador de Caminhão & $3.181,89$ & 2 & $6.363,78$ \\
\hline Operador de Carregadeira & $3.181,89$ & 2 & $6.363,78$ \\
\hline Operador Processamento & $3.181,89$ & 3 & $9.545,67$ \\
\hline Técnico em Mineração & $3.743,40$ & I & $3.743,40$ \\
\hline Combustível Caminhão & 616,90 & 2 & I.233,79 \\
\hline Combustível Escavadeira & $4.458,24$ & 2 & $8.916,48$ \\
\hline Desmonte & $100.000,00$ & I & $100.000,00$ \\
\hline Alimentação & 98,00 & 20 & $1.960,00$ \\
\hline Energia & $33.000,00$ & I & $33.000,00$ \\
\hline Manutenção & $355.500,00$ & I & $355.500,00$ \\
\hline PIS/CONFIS/Outros & $1.000,00$ & I & $1.000,00$ \\
\hline Part. Proprietário do Solo & $1.000,00$ & I & $1.000,00$ \\
\hline IR & $1.000,00$ & I & $1.000,00$ \\
\hline ICMS & $1.000,00$ & I & $1.000,00$ \\
\hline \multirow[t]{2}{*}{ Outros } & $10.000,00$ & I & $10.000,00$ \\
\hline & & TOTAL & $R \$ 559.566,36$ \\
\hline
\end{tabular}

A Proposta I (Figura 2) consiste no pagamento do investimento de $R \$ 3.806 .586,00$ em 24 parcelas com juros de $0,73 \%$ a.m., resultando em parcelas de $R \$ 173.379,41$. Logo, são necessários dois empréstimos nos valores de $\mathrm{R} \$ 203.409,77$ e $\mathrm{R} \$ 26.897,77$ nos dois primeiros meses. Com juros de 4,39\% a.m., o primeiro empréstimo teve juros capitalizados por dois meses, e o segundo empréstimo por um mês, até o pagamento de ambos em três parcelas de $R \$ 90.517,97$ logo no terceiro mês de funcionamento do empreendimento. Ao final, a proposta I gerou $\mathrm{R} \$ 395.766,18$ em juros.

Na Proposta 2 (Figura 3) o pagamento do investimento foi realizado em 12 parcelas de $R \$ 332.362,23$, sendo necessários três empréstimos de $R \$ 362.392,59, R \$ 185.880,59$ e $R \$ 9.368,59$. Foram geradas cinco parcelas de $R \$ 141.275$, I8, que começaram a ser pagas no mês seguinte, após o último empréstimo. $O$ total de juros da Proposta 2 chegou a $\mathrm{R} \$ 330.494,95$. 


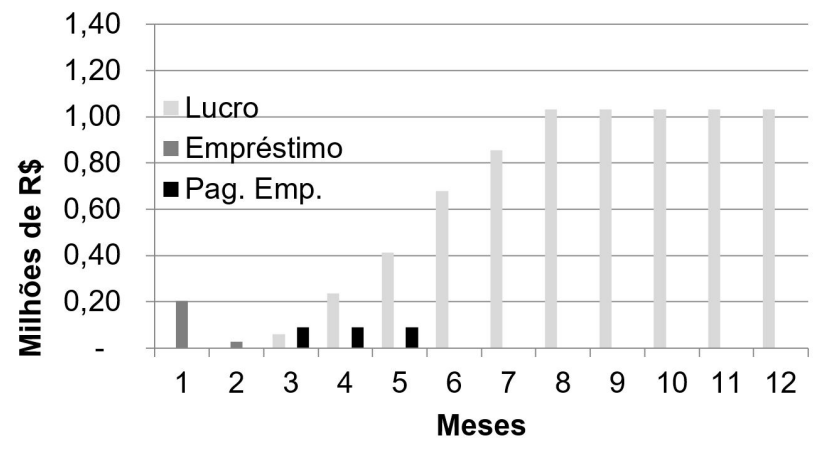

Figura 2. Proposta I para pagamento do CAPEX iniciando-se no primeiro mês, parcelado em 24 vezes.

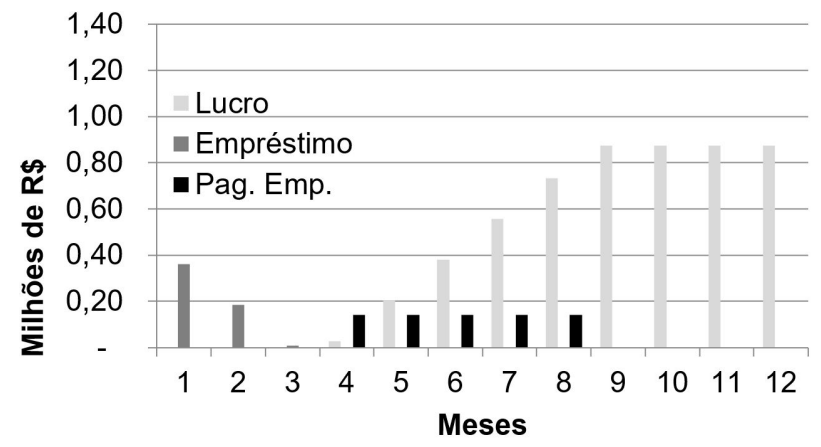

Figura 3. Proposta 2 para pagamento do CAPEX iniciando-se no primeiro mês, parcelado em 12 vezes.

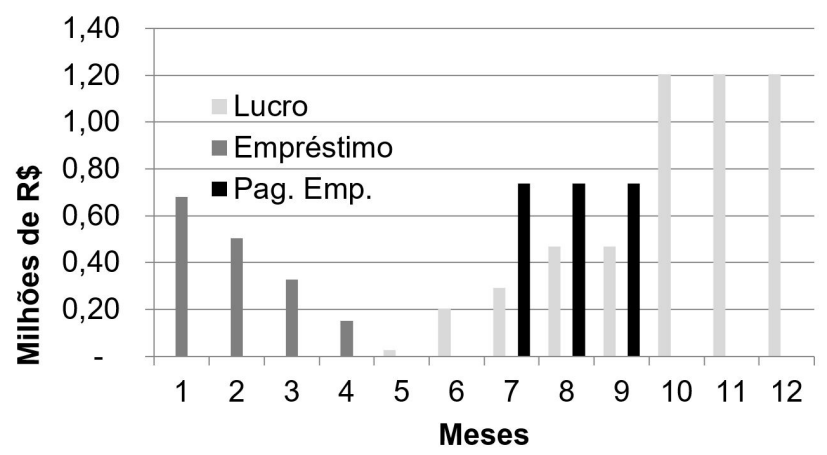

Figura 4. Proposta 3 para pagamento do CAPEX iniciando-se no primeiro mês, parcelado em 6 vezes.

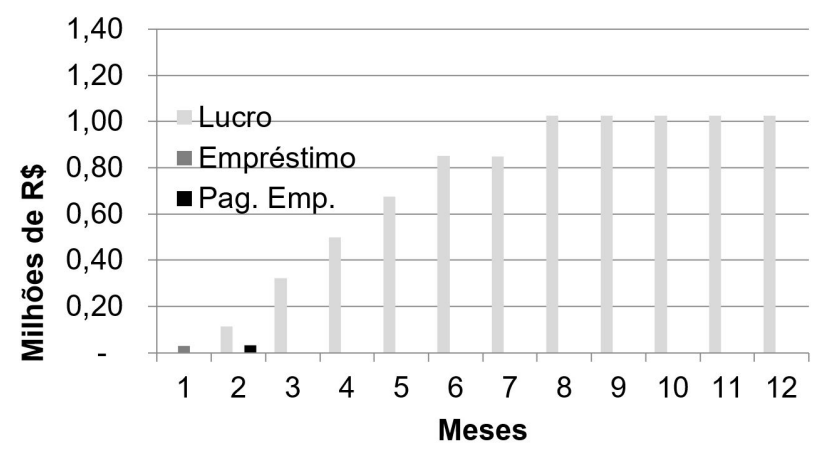

Figura 5. Proposta 4 para pagamento do CAPEX iniciando-se no sexto mês, parcelado em 24 vezes.

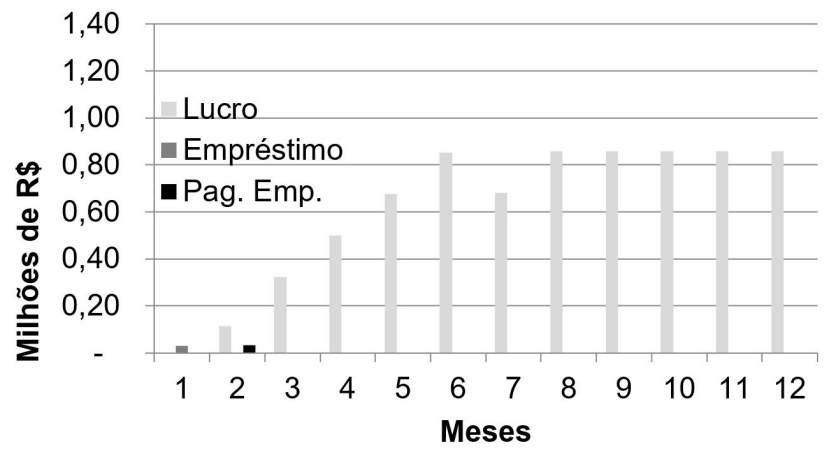

Figura 6. Proposta 5 para pagamento do CAPEX iniciando-se no sexto mês, parcelado em 12 vezes.

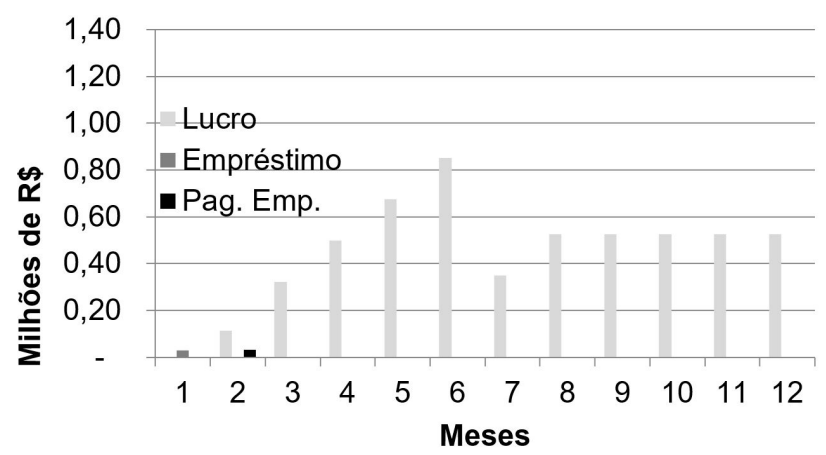

Figura 7. Proposta 6 para pagamento do CAPEX iniciando-se no sexto mês, parcelado em 6 vezes.

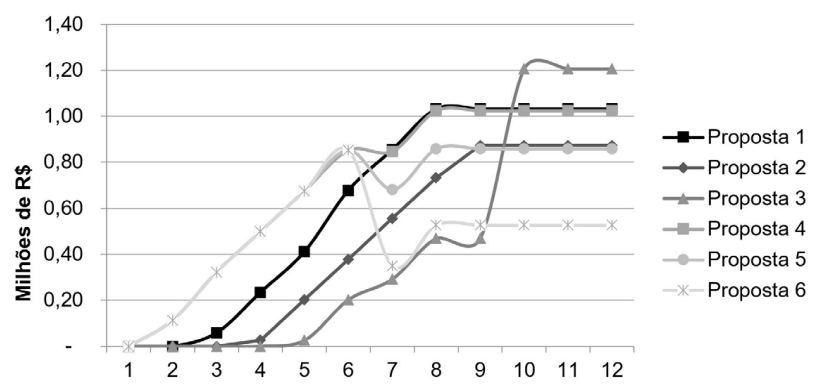

Figura 8. Comparação entre os lucros obtidos em cada proposta.

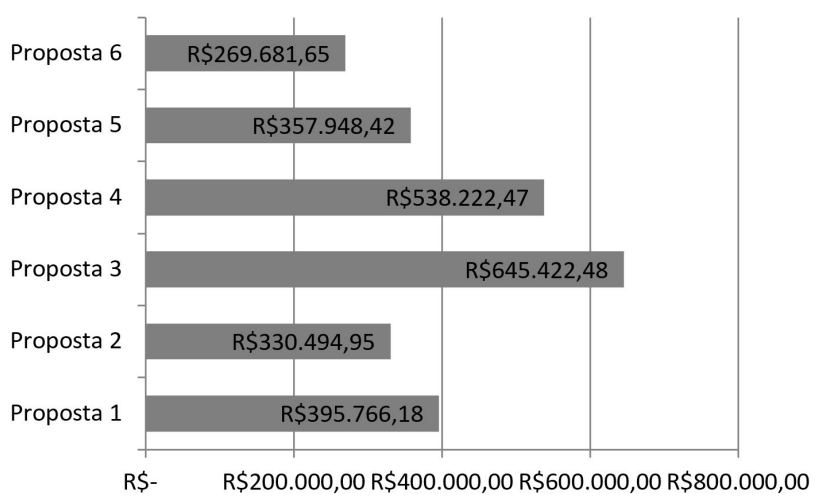

Figura 9. Comparação dos juros pagos em cada proposta. 
A Proposta 3 (Figura 4) realiza o pagamento do investimento em 6 parcelas de $R \$ 650.626,60$, fazendo-se necessário quatro empréstimos de $R \$ 680.656,95, R \$ 504.144,95$, $R \$ 327.632,95$ e $R \$ 15 I$. I 20,95, que capitalizaram juros por seis, cinco, quatro e três meses, respectivamente, já que o pagamento das parcelas do empréstimo só começou no sétimo mês para não negativar o lucro da empresa. Foram necessárias três parcelas de $R \$ 737.268,24$ e, consequentemente, foram gerados na totalidade $\mathrm{R} \$ 645.442,48$ de juros.

Para as demais três propostas (Figuras 5, 6 e 7) o investimento inicial de $R \$ 3.806 .586,00$ sofreu uma capitalização de juros por seis meses, resultando em $\mathrm{R} \$ 3.972 .172,49$. A partir deste último valor foram avaliadas as demais propostas.

As propostas 4, 5 e 6 se diferenciam pela quantidade de parcelas para o pagamento do investimento em 24 , 12 e 6 vezes, cujos valores são de $R \$ 180.921$, 41 , $R \$ 346.819,99$ e $R \$ 678.928,85$, respectivamente. Como - pagamento do investimento só aconteceu seis meses após a abertura da pedreira, em todos os três casos foram necessários apenas um único empréstimo de $R \$ 30.030,36$, que foi capitalizado somente por um mês e pago em somente uma parcela de $R \$ 32.724,90$. A diferença fica nos juros totais gerados. A proposta 4 gerou um total de $\mathrm{R} \$ 538.22,47$, contra $\mathrm{R} \$ 357.948,42$ da proposta 5 e $R \$ 269.68 \mathrm{I}, 65$ da proposta 6 .

\section{CONCLUSÃO}

O pagamento rápido do CAPEX gera juros menores, 0 que nem sempre é vantajoso. Poucas parcelas proporcionam valores altos que não acompanham o crescimento do empreendimento, influenciando drasticamente no lucro dos primeiros meses de operação. Torna-se necessário empréstimos com altos juros para manter o equilíbrio financeiro, levando a um montante final de juros alto, como na proposta 3.

A proposta 6 apresenta situação interessante, com equilíbrio entre número de parcela para pagamento do CAPEX e quantidade de empréstimos necessários para manter o equilíbrio financeiro do empreendimento nos meses iniciais. Entretanto, a queda nos lucros acontece em meses posteriores, fato contrário ao apresentado pela proposta 2.

Portanto, o melhor cenário de retorno do investimento é variável e depende do interesse dos investidores. A proposta 6 oferece menores juros e um maior lucro anual se comparado a proposta 2 , mas sofre uma baixa de lucros a partir do sétimo mês, podendo restringir investimentos futuros almejados pelo empreendimento. Inversamente, a proposta 2 oferece, com o ônus de uma taxa de juros superior, um lucro maior a partir do sétimo mês e melhor distribuído.

\section{REFERÊNCIAS}

I Christmann RA. Análise de investimentos - um sistema de apoio à decisão [monografia]. Lajeado: Centro Universitário Univates, 2009. [acesso em 18 abr. 2018]. 87 p. Disponível em: https://www.univates.br/bdu/ handle/ $10737 / 588$

2 Puccini EC. Matemática financeira e análise de investimentos. Florianópolis: UAB; 201 I.

3 Jesus JNP, Souza CA, Dalfior VAO. Fluxo de caixa como instrumento de gestão. In: Associação Educacional Dom Bosco. Anais do XII SEGeT - Simpósio de excelência em gestão e tecnologia; 28, 29 e 30 de outubro de 20I5; Rezende/R], Brasil. Rezende: AEDB, 2015 [acesso em 18 abr. 2018]. Disponível em: https://www.aedb.br/seget/ arquivos/artigos 15/5 12247.pdf

4 Gimenes AA, Francisco DF, Silva ETG. Fluxo de caixa. In: Centro Universitário Católico Salesiano. Anais do III Encontro Científico e Simpósio de Educação Unisalesiano; 20II Outubro I7-2I; Lins, Brazil. Lins: UNISALESIANO, 20I I [acesso em I8 abr. 2018]. Disponível em: http://www.unisalesiano.edu.br/simposio20I I/publicado/artigo008I.pdf

5 Pivetta G. A utilização do fluxo de caixa nas empresas: Um modelo para a pequena empresa. Revista Eletrônica de Contabilidade, 2005 [acesso em I 8 abr. 20 I8]; I (2). Disponível em: <https://periodicos.ufsm.br/contabilidade/ article/view/6229/3729

6 Instituto Brasileiro de Mineração - IBRAM. Portal da mineração. Belo Horizonte: IBRAM; 2018 [acesso em I8 abr. 20l8]. Disponível em: http://portaldamineracao.com.br/wp-content/uploads/20I8/02/economia-mineralbrasil-mar20 18-2.pdf?x73853

7 Quaresma LF. Relatório técnico 30: Perfil de brita para construção civil. Belo Horizonte: J. Mendo Consultoria; 2009 [acesso em 18 abr. 2018]. Disponível em: http://www.jmendo.com.br/wp-content/uploads/201 I/08/P22_RT30_ Perfil_de_brita_para_construxo_civil.pdf

8 Instituto Brasileiro de Geografia e Estatística - IBGE. Censo demográfico. Rio de Janeiro: IBGE; 2018 [acesso em 13 abr. 2018]. Disponível em: https://www.ibge.gov.br/estatisticas-novoportal/sociais/saude/9662-censodemografico-2010.html? =\&t=resultados

9 Instituto Brasileiro de Geografia e Estatística - IBGE. Estimativas da população. Rio de Janeiro: IBGE; 20 I8 [acesso em I3 abr. 2018]. Disponível em: ftp://ftp.ibge.gov.br/Estimativas_de_Populacao/Estimativas_2016/estimativa_dou_2016_20160913.pdf 
Mendes et al.

10 Instituto Mauro Borges de Estatística e Estudos Socioeconômicos - IMB. Produto interno bruto dos municípios goianos. Goiânia: IMB; 2018 [acesso em I 3 abr. 20I8]. Disponível em: http://www.imb.go.gov.br/

II Britanite. Densidade média de materiais. São Paulo: Britanite; 2018 [acesso em I8 abr. 20 I8]. Disponível em: http:// www.integracenter.com.br/portfolio/britanite/densidade.html

I2 Máquinas BRASIF. [página da internet]. [acesso em 10 abr. 20 I8]. Disponível em: http://www.brasifmaquinas.com.br/

I 3 Sindicato da Indústria da Construção no Estado de Goiás - SINDUSCON-GO. Custos unitários básicos de construção. Goiânia: SINDUSCON-GO; 2018 [acesso em 8 mar. 2018]. Disponível em: http://www.sinduscongoias. com.br/arquivos/download/cub/cub-fevereiro-2018.pdf

I4 Britago [página da internet]. [acesso em 10 abr. 20 18]. Disponível em: http://britago.com.br/

I5 Pedreira Goiás [página da internet]. [acesso em 10 abr. 20 I8]. Disponível em: http://www.pedreiragoias.com.br/

I6 Banco Central do Brasil. Histórico das taxas de juros. Brasília: BCB; 2018 [acesso em I4 abr. 20 I8]. Disponível em: https://www.bcb.gov.br/Pec/Copom/Port/taxaSelic.asp

Recebido em: 13 Jul. 2018

Aceito em: 19 Jun. 2019 